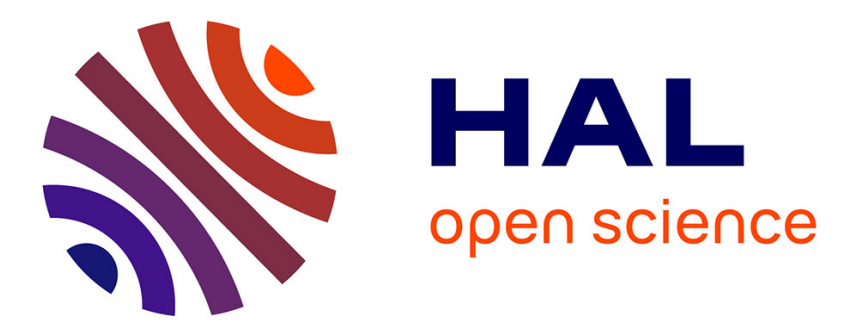

\title{
Carbohydrate-derived unsaturated polyester for high bio-based carbon content photopolymer
}

Aymeric Champion, Xavier Allonas, Céline Croutxé-Barghorn, Anne-Sophie Schuller, Christelle Delaite

\section{- To cite this version:}

Aymeric Champion, Xavier Allonas, Céline Croutxé-Barghorn, Anne-Sophie Schuller, Christelle Delaite. Carbohydrate-derived unsaturated polyester for high bio-based carbon content photopolymer. Progress in Organic Coatings, 2019, 131, pp.240 - 246. 10.1016/j.porgcoat.2019.02.026 . hal03486868

\section{HAL Id: hal-03486868 \\ https://hal.science/hal-03486868}

Submitted on 20 Dec 2021

HAL is a multi-disciplinary open access archive for the deposit and dissemination of scientific research documents, whether they are published or not. The documents may come from teaching and research institutions in France or abroad, or from public or private research centers.
L'archive ouverte pluridisciplinaire HAL, est destinée au dépôt et à la diffusion de documents scientifiques de niveau recherche, publiés ou non, émanant des établissements d'enseignement et de recherche français ou étrangers, des laboratoires publics ou privés.

\section{()ㅜ(1)}

Distributed under a Creative Commons Attribution - NonCommerciall 4.0 International 


\title{
Carbohydrate-derived unsaturated polyester for high bio-based carbon content photopolymer
}

\author{
Aymeric Champion ${ }^{\mathrm{a}, \mathrm{b}}$, Xavier Allonas ${ }^{\star a}$, Céline Croutxé-Barghorn ${ }^{\mathrm{a}}$, Anne-Sophie Schuller ${ }^{\mathrm{b}}$, \\ Christelle Delaite $^{a}$ \\ 'Laboratoire de Photochimie et d'Ingénierie Macromoléculaires, Université de Haute Alsace, \\ Mulhouse ; xavier.allonas@uha.fr \\ ${ }^{\text {b} M a ̈ d e r ~ G r o u p, ~} 130$ rue de la Mer Rouge, 68200 Mulhouse, France
}

\begin{abstract}
This paper focuses on the study of thermomechanical properties of polyester acrylate (PEA) resins based on poly(butylene succinate) (PBS) and isosorbide with incorporation of $1 /$ diacid chains ranging from succinic acid (C4) to azelaic acid (C9) and 2/ diols with various structures such as butanediol and poly(ethyleneglycol) (PEG) with the aim to affect the stiffness of photopolymerized coatings. Therefore, statistic polyester acrylates of $\mathrm{Mn}$ $600 \mathrm{~g} / \mathrm{mol}$ with low polydispersity and Tg were successfully synthetized and characterized by SEC, DSC and DMA. The relative acid value is between 60 and $80 \mathrm{mgKOH} / \mathrm{g}$ and the biorenewable carbon content can reach 71 to $90 \%$. Incorporation of the different diols in the backbone was confirmed by NMR. The mixtures of mono and difunctionnal oligomers were crosslinked under LED irradiation and benefits from flexible chain extenders was enlighetened first from improved rate of polymerization and with higher conversion.
\end{abstract}

\section{Keywords}

Biobased, Polyester acrylate, Photopolymerization, Isosorbide

\section{Introduction}

Given the significant volatility in oil prices these last decades, and the ecological impact of the oil shale, substitutes to petroleum-based chemicals have been developed from biomassderived materials in the framework of the twelve principles of green chemistry developed in 1998. Biobased monomers with reduced footprint impact have shown a great interest in the field of photopolymers where the keypoint is to reduce energy and time process. In polymeric coatings, photocurable formulation allows higher application speed and solvent-free reaction at room temperature [1]. There are two ways to use biomass-derived chemicals in polymer industry.

The first one consists in the synthesis of the same backbone as the petroleum-based one. However, just few bio-based compounds may compete with their petro-analogs because of 
their higher price of production. For example, 1,4-butanediol (BD) is conventionally produced using acetylene-based process and can be obtained from bio-succinic acid (SA) and glucose fermentation [2]. The new biorefinery can use waste from agriculture to produce useful building-block like adipic (C6), azelaic (C9) or longer diacid [3]. Ethylene glycol is produced for many years from bio-ethanol [4] and more recently, different sized bio-based polyethylene glycol (PEG) from sugarcane were marketed.

The second way is to innovate and use specific backbones which could be found from renewable materials. From that perspective, the trickiest part is to afford new final structures which could match to the specific requirements of the industry. Two main examples are the triglyceride vegetable oils and polysaccharides. For example, triglycerides have been used as low cost flexible spacer for photocurable wood coating [5] or Braille embossing [6] after direct functionalization of the unsaturation. On the other hand, vegetable oils can be used for the production of liquid fatty acid like the sebacid acid monomer [7]. The process is shown on Figure 1.

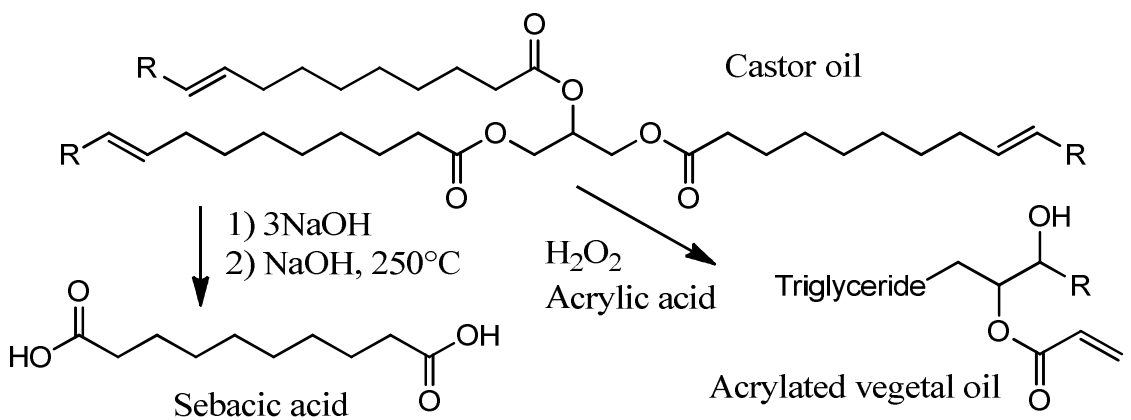

Figure 1: Example of pathway to produce different synthons from bio-oil.

In the case of polysaccharides, the mostly used synthon is isosorbide which is a rigid chiral spacer. It synthesis proceeds from starch which can be extracted from corn and degraded into d-glucose and d-mannose by an enzymatic process [8]. Secondly, d-sorbitol and dmannitol are obtained by hydrogenation and finally, the products are dehydrated in order to obtain isosorbide (Figure 2). Cellulose can also be used as raw material to produce isosorbide [9]. 


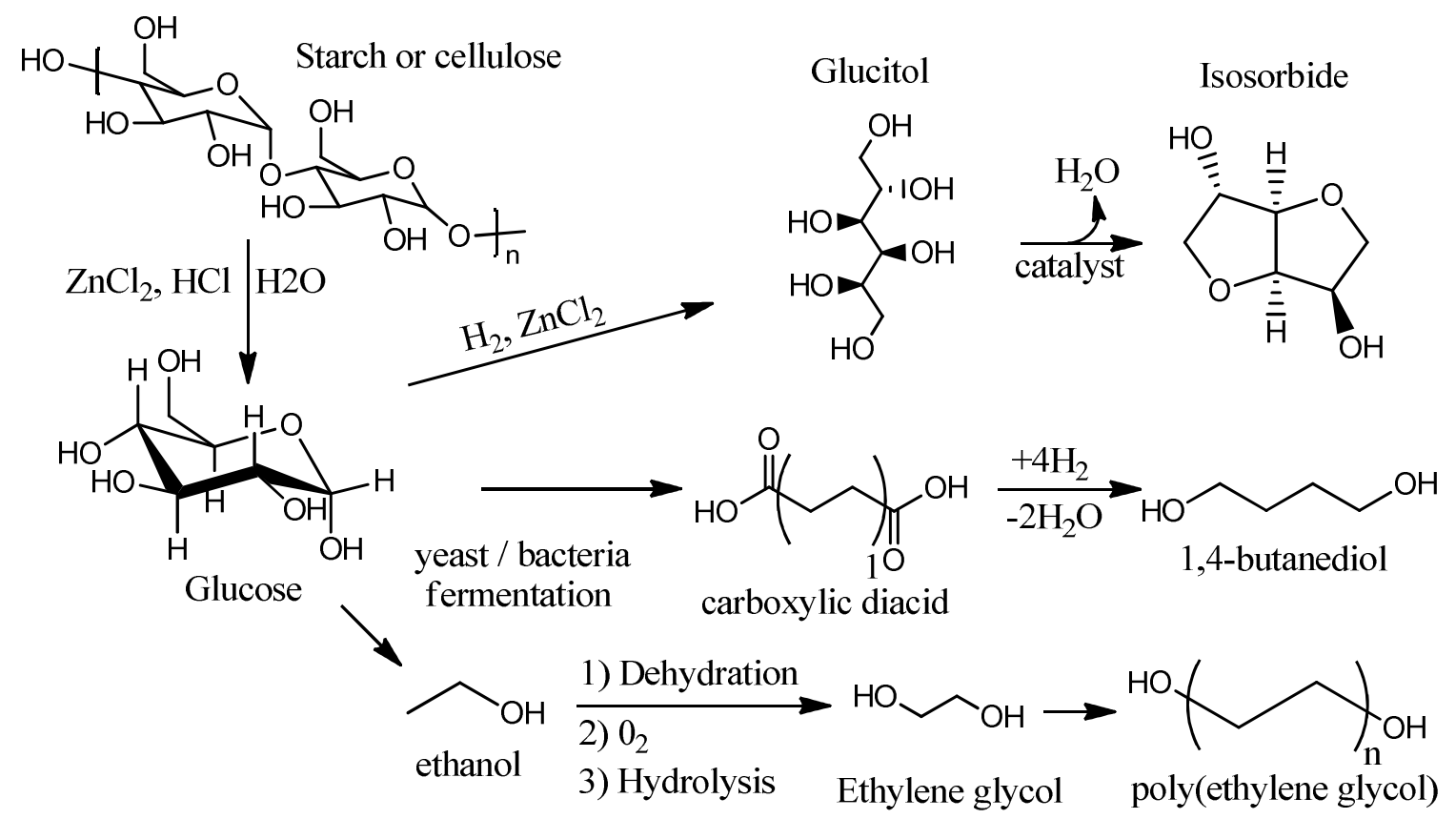

Figure 2: Example of pathway to produce the different synthons from carbohydrates

Due to its rigid structure, isosorbide has been expected to be a good candidate for the replacement of bisphenol A-like structure, while keeping good mechanical properties and transparency. Indeed, the isohexide is composed of 2 tetrahydrofuran rings fused together with an angle of $120^{\circ}$ which lead to a V-shaped molecule. However, the endo and exo hydroxyl groups won't have the same reactivity in esterification depending of the steric requirements and intramolecular hydrogen bonding [10], which can make more difficult the functionalization [11].

Isosorbide thus appears to be an interesting bio-based compound for the synthesis of resins usable in coating applications. Therefore, (un)saturated polyester resins were synthesized, leading to thermoplastics [12], thermosets [13-16] and even oligomeric chains using di(meth)acrylate of isosorbide used [17]. These applications gave promising mechanical and thermal properties. Isosorbide di(meth)acrylate has been used also thermopolymerizatrion [18-19] and photopolymerization [20-24]. The effect of isosorbide on the final properties of classical unsaturated polyesters like polybutylene succinate [25-27] has been studied, but the importance of the spacer for increasing the mobility of the backbone has not been investigated so far for the polyester acrylate in photopolymerization. 
This paper focuses on the photopolymerization process polyester acrylates based on isosorbide as hard segments and soft segments built either from diacid chain or additional diol. In particular, the impact of the soft segments on the final properties of the polyester acrylate resins was investigated. These soft segments aim to counterbalance the restricted rotation attributed to the stiff bicycle of the isosorbide. The low reactivity of isosorbide is used to synthesize low molar mass oligomers with tuned properties thanks to different bio-based synthons with the aim to fulfill industrial requirements such as high rate of polymerization, good adhesion on substrate, low shrinkage, low viscosity and low yellowing. Then, the polyester acrylate resins were formulated and characterized for LED-curing at $395 \mathrm{~nm}$ using isopropylthioxanthone (ITX) as photoinitator and ethyl-4-(dimethylamino)benzoate (EDB) as hydrogen donor.

\section{Materials and Methods}

Materials.

Isosorbide (IS, >99.8\%, Roquette), succinic acid (C4, 99\%, Fischer Scientific), adipic acid (C6, 99\%, Fischer Scientific), azelaic acid (C9, 98\%, Fischer Scientific), 1,4-butanediol (BD, >99\%, Fischer Scientific), poly(ethylene glycol) (PEG200, average M.W. 200g/mol Fischer Scientific), were used as precursors for the polycondensation of polyesters.

Acryloyl chloride (96\%, Fischer Scientific), triethylamine (TEA, 99\%, Fischer Scientific), dichloromethane (DCM, 100\%, VWR), trifluoroacetic anhydride, (TFAA, >99\%, Fischer Scientific), deuterochloroform $\left(\mathrm{CDCl}_{3}, 99.8 \%, \mathrm{VWR}\right) \alpha, \alpha, \alpha$-trifluorotoluene (TFT, $>99 \%$, Fischer Scientific), sodium bicarbonate $\left(\mathrm{NaHCO}_{3}, 99.5 \%\right.$, Acros Organics), magnesium sulfate anhydrous (>95\%, Acros Organics), sodium chloride ( $\mathrm{NaCl}, \mathrm{VWR})$, 4-methoxyphenol (MEHQ, 99\%, Acros Organics) were used for the acrylation of the synthesized polyesters.

Allyl bromide (99\%, Acros Organics), tetraetylammonium bromide (98\%, Acros Organics), methacrylic acid (99.5\%, Fischer Scientific), 3-chloroperoxybenzoic acid (70-75\%, Acros Organics) were used for the synthesized of isosorbide glycidyl methacrylate (ISGMA).

A mixture of 2- and 4-isopropylthioxanthone (Esacure ITX, IGM), Ethyl-4(dimethylamino)benzoate (Esacure EDB, IGM) were used for photopolymerization as a gift from Lamberti. Tetrahydrofurfuryl acrylate (THFA, Sarbio 5100), isobornyl acrylate (IBOA, Sarbio 5102), 1,10-decanediol diacrylate (3DA, Sarbio 5201), 1,6-hexanediol diacrylate (HDDA, SR238) were obtained as a gift from Sartomer.

All chemicals were used as received. 
Methods.

Synthesis:

Synthesis of isosorbide based PEAs. A typical polycondensation of oligomer was conducted on a heating mantle in a multi-necked flask with a nitrogen inlet, mechanical stirrer, DeanStark outfitted with a condenser in order to trap the water from the reaction. The reaction began under nitrogen flow at $90^{\circ} \mathrm{C}$ in order to obtain a liquid mixture and avoid sublimation of the diacid while removing all of the oxygen in the medium. Override this step will lead to yellow humins formation from isosorbide. There was a second step at $150^{\circ} \mathrm{C}$ during 2 hours to extend the macromolecule. Finally, the condensation was pushed under nitrogen flow that carried the water out of the medium at $190^{\circ} \mathrm{C}$ for $5 \mathrm{~h}$.

Acrylation of isosorbide based PEAs. Hydroxyl-terminated polyester $(200 \mathrm{~g})$ and dichloromethane $(\mathrm{DCM}, 600 \mathrm{~mL})$ were added in a three-necked flask equipped with a stirrer and were stirred while in an ice bath $\left(0-5^{\circ} \mathrm{C}\right)$. Acryloyl chloride (1.3eq per $\mathrm{OH}$ function) was then added drop wise during 5 hours, and triethylamine (1.3eq per $\mathrm{OH}$ function) was added to the system. After stirring for a night at room temperature, the white solid of triethylamine hydrochloride was removed via simple filtration. The organic phase was then washed three times with aqueous saturated $\mathrm{NaHCO}_{3}$ and then $\mathrm{NaCl}$. The organic phase was then dried over anhydrous $\mathrm{MgSO}_{4}$ and $\mathrm{MEHQ}$ was added before being concentrated under reduced pressure.

Isosorbide diglycidyl ether methacrylate (ISGMA) was synthesized according to the literature [28].

\section{Characterizations}

Molecular weight $(\mathrm{Mn})$ determination was carried out using a size exclusion chromatography (SEC) Shimadzu LC-20AD liquid chromatograph equipped with two Varian PL gel $5 \mu \mathrm{m}$ MIXED-C columns and a refractive index detector (Shimadzu RID-10A) with a polystyrene calibration in THF. Mn was also calculated from the acid value after the end of the condensation. The acid value (AV) is defined as the number of milligrams of potassium hydroxide $(\mathrm{KOH})$ required to neutralize $1 \mathrm{~g}$ of polymer resin. When there is an imbalance in the stoichiometry of the reactants, the average degree of polymerization follows the next equation: 
$\mathrm{DP}_{\mathrm{n}}=\frac{M_{\mathrm{n}}}{\mathrm{M}_{o}}$ and $\mathrm{DP}_{\mathrm{n}}=\frac{1+\mathrm{r}}{1+\mathrm{r}-2 \mathrm{rp}}$, the stoichiometric ratio $: r=\frac{\mathrm{nCOOH}}{\mathrm{nOH}}\left(\mathrm{r}_{\text {theo }}=\frac{1}{1.3}\right.$ for terpolyester $)$, the conversion : $\mathrm{p}=\frac{\mathrm{nCOOHinitial/g-nCOOHfinal/g}}{\mathrm{nCOOHinitial/g}}$ with the number of moles of acid function per gram of resin at $\mathrm{t}: \mathrm{nCOOHf} / \mathrm{g}=\frac{\mathrm{AV} * 0.001}{\mathrm{MMKOH}}$ with $M M K O H$ the molar mass of $\mathrm{KOH}$.

Proton NMR analysis was performed in $\mathrm{CDCl}_{3}$ at $20^{\circ} \mathrm{C}$ on a Bruker $400 \mathrm{MHz}$ spectrometer. Hydroxyl end-group chemical titration was performed by ${ }^{1} \mathrm{H}-\mathrm{NMR}$ according to a derivation method. After dissolution of $10 \mathrm{mg}$ of the synthesized polyester in $0.6 \mathrm{~mL}$ of $\mathrm{CDCl}_{3}, 20 \mu \mathrm{L}$ of trifluoroacetic anhydride was added and stirred for a night. $10 \mathrm{mg}$ of trifluorotoluene was then added to the mixture as standard and the hydroxyl content was calculated from the shift.

The content of difunctionnal oligomers $2 f \%$ compared to monofunctionnal was calculated with the following equation:

$2 f \%=100 * \frac{n_{\text {macromolecule }}-n_{\text {terminaison- } \mathrm{COOH}}}{n_{\text {macromolecule }}}$ and $n_{\text {macromolecule }}=\frac{n_{\text {terminaison-OH }}+n_{\text {terminaison-COOH }}}{2}$

Absorbance spectra were obtained in dichloromethane using a $1 \mathrm{~cm}$ quartz cell and recorded on a Specord 210 AnalytikJena UV-Visible spectrophotometer.

Rheology study was performed using a MCR302 photorheometer from Anton Paar in a range of 1 to $100 \mathrm{~s}^{-1}$ in order to have a linear evolution at $25^{\circ} \mathrm{C}$ with a gap of $0.5 \mathrm{~mm}$ between the parallel plate and the glass.

Proton NMR analysis was performed in $\mathrm{CDCl}_{3}$ at $20^{\circ} \mathrm{C}$ on a Bruker $400 \mathrm{MHz}$ spectrometer.

Differential scanning calorimetry (DSC) analyses were conducted with a TA instruments Q200 apparatus under nitrogen atmosphere to determine the glass transition temperature. The temperature over the range from $-80^{\circ} \mathrm{C}$ to $200^{\circ} \mathrm{C}$ was increased at a heating rate of 20 ${ }^{\circ} \mathrm{C} \cdot \mathrm{min}^{-1}$. The glass transition temperature $\mathrm{Tg}$ was chosen as the midpoint of the heat capacity change from a second cycle.

Time-resolved Fourier transform infrared spectroscopy (RT-FTIR) was used to measure the double bond $[C=C]_{0}$ conversion of resins on $\mathrm{KBr}$ substrates with a Vertex $70 \mathrm{FTIR}$ spectrophotometer from Bruker Optics. Scans were taken every $120 \mathrm{~ms}$ with a MCT $160 \mathrm{kHz}$ in transmission mode at a resolution of $4 \mathrm{~cm}^{-1}$. Kinetic measurements were performed under a UWAVE LED at $395 \mathrm{~nm}$ operating at $100 \mathrm{~mW} / \mathrm{cm}^{2}$. The intensity of the lamp was measured using a spectrometer Ocean Optics. The area of the elongation of the acrylate band at 811 $\mathrm{cm}^{-1} A_{t}^{811}$ was used to monitor the reaction, taking the aromatic $v_{\mathrm{C}=\mathrm{C}}$ stretching band of EDB at $1608 \mathrm{~cm}^{-1} A_{t}^{1608}$ as the reference in order to avoid external perturbations like depth modification. The 2 bands around $1635 \mathrm{~cm}^{-1}$, from the cis- and trans- conformers of acrylate 
[29], corresponding to the $v_{\mathrm{C}=\mathrm{C}}$ stretching region were not used because of an overlapping with EDB. The conversion DC\% and the rate of polymerization Rp were then calculated as follows:

$D C \%=1-\frac{A_{t}^{811} / A_{t}^{1608}}{A_{0}^{811} / A_{0}^{1608}}, R p=\frac{D C \% *[C=C]_{0}}{d t}$ and $[C=C]_{0}=\frac{f(\text { functionnality })}{M n(\text { molar mass })}$ or $=n_{\text {terminaison }-\mathrm{OH}}$

Photopolymerization experiments for DMA were performed by spreading the formulation on a treated-polypropylene foil and normalized with a $80 \mu \mathrm{m}$ bar coater before irradiation. Irradiation was operated using a FireJet FJ200 from Phoseon having a maximal intensity of $12 \mathrm{~W}$ and a irradiance around $395 \mathrm{~nm}$. The sample received a dose of $1 \mathrm{~J} / \mathrm{cm}^{2}$ measured with a spectral radiometer UV-PAD from Opsytec Dr Gröbel.

Dynamic Mechanical Analysis (DMA) were conducted with a TA instruments Q800 apparatus A heating rate of $3{ }^{\circ} \mathrm{C} / \mathrm{min}$ was employed throughout to ensure that the sample, a thin film (width of $5.3 \mathrm{~mm}$ and length of $20 \mathrm{~mm}$ ), was in thermal equilibrium with the instrument. The temperature range was $-50-150{ }^{\circ} \mathrm{C}$ for two cycles. The oscillating frequency was set at $1 \mathrm{~Hz}$ with an amplitude of $20 \mu \mathrm{m}$, a static pre-load force of $0.005 \mathrm{~N}$ and a force track of $125 \%$. T $\alpha$ and $\mathrm{Tg}$ from the maximum $\tan \delta$ were determined at the second cycle respectively as the temperature at the maximum of the loss modulus and tan $\delta$ in function of the temperature. The full width at half maximum (FWHM) was measured from the alpha transition of loss modulus. Then, the storage modulus at $150^{\circ} \mathrm{C}$ was used in order to estimate the crosslinking density of the photopolymerized film with the following equation [30]:

$M c=\frac{G^{\prime}>T g}{3 \rho R T}$ and $X c=\frac{1}{M c}$

where $\mathrm{Mc}$ is the average distance between two crosslink nodes, $\mathrm{Xc}_{\mathrm{c}}$ is the crosslink density in the rubbery state, $G^{\prime}$ is the storage modulus at the rubbery state, $\rho$ is the film density determined with a pycnometer, $\mathrm{R}$ is the gas constant, and $\mathrm{T}$ is the absolute temperature.

The biorenewable carbon content BRC was estimated according to [30]:

$\boldsymbol{B}_{\boldsymbol{i}}=\frac{\text { C biobased }}{C \text { biobased }+ \text { C petrobased }}$ and $B R C=100 * \sum_{i=1}^{n} \boldsymbol{B}_{\boldsymbol{i}} * f_{i}$

with $B_{i}$ the content of biobased carbon in the macromolecule, $f_{i}$ the fraction of the macromolecule i in the formulation. 


\section{Results and Discussion}

Synthesis

Several unsaturated oligomers and monomers were synthesized with an isosorbide-core and the impact of the soft segment on the photochemical and thermal behavior was investigated. A schematic representation of the oligomers synthesized during this work is shown in Figure 3. Apart the isosorbide and the acrylate groups, a second diol can be used as chain extender which is, in our case, butanediol or poly(ethyleneglycol). In addition, the length of the diacid can also be modified, from succinate acid (C4) to azelaic acid (C9). Two supplementary oligomers were synthesized for sake of reference compounds, based on isosorbide and succinic acid (oligo[IS:SA]) or butanediol and succinic acid (oligo[BD:SA]). During the bulk polymerization, condensation was limited and high acid value was obtained.

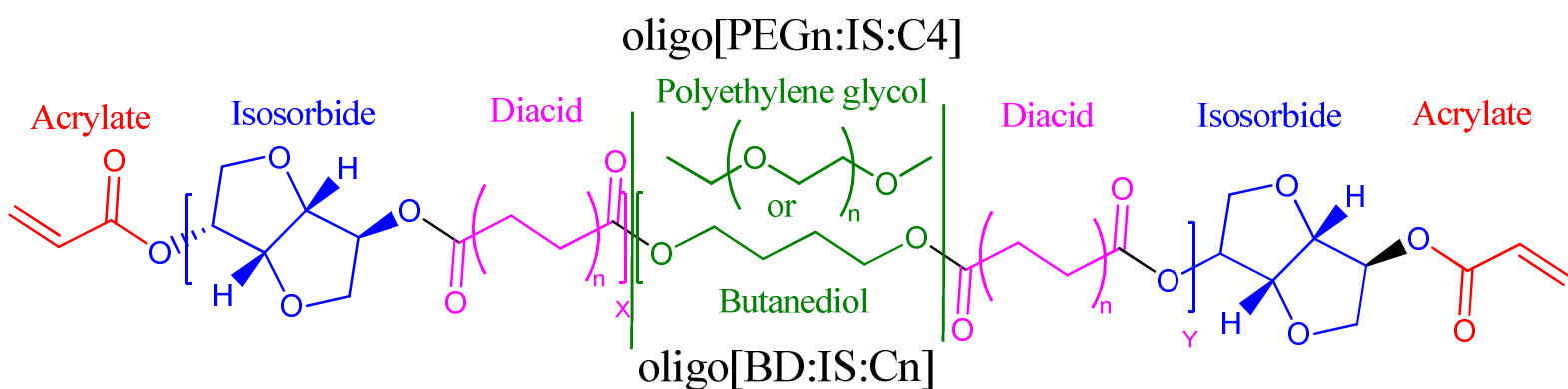

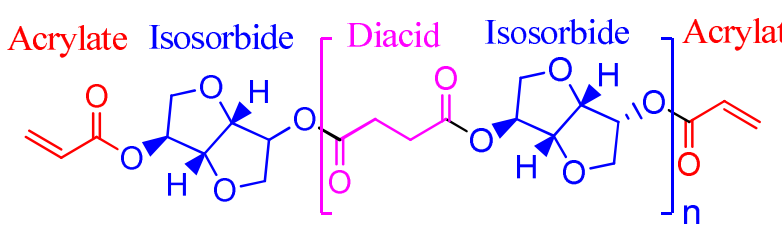

oligo[IS:C4]

Acrylate Butanediol Diacid Butanediol Acrylate<smiles>C=CC(=O)OCCCCOC(=O)CCC(=O)OCCCCOC(=O)C=C</smiles>

oligo[BD:C4]

Figure 3: Chemical structure of the synthesized polyesters acrylates oligomers.

After the bulk polycondensation, integration of the isosorbide into the backbone was checked by NMR. Figure 4 shows the ${ }^{1} \mathrm{H}$-NMR spectrum and shift assignments of one of the oligomers synthesized. The effect of isosorbide content on properties being already studied $[14,17]$, the molar ratio of isosorbide in the present work was kept constant (75 mol.\% of total diols) for all the oligomers synthesized and the ratio $n_{\text {diol }}: n_{\text {diacid }}$ was $1.3: 1$ in order to have isosorbide terminaisons.. The composition of the different oligomers is shown in Table 1. As expected from the reactivity of the endo hydroxyl group, most of the products have a molar ratio BD:IS:Cn close to 0.44:0.86:1 (Feed molar ratio was 0.33:0.97:1). Moreover, it can be noted from the conversion, that higher final molar ratio in isosorbide could be related to lower acid value. After the acrylation step, end-group of isosorbide can still be observed (c', f', d' in Figure 4), although at very low intensity. Hydroxyl value and acid value were thus used to 
distinguish the end-groups of the final oligomer and confirmed that the hydroxyls were not fully acrylated. All the peaks between 5.5 and $7 \mathrm{ppm}$ correspond to carbon double bonds and precise determination was not possible because of the effect of endo/exo configuration of the initial hydroxyl terminaison. Acryloyl chloride was chosen because of its high reactivity towards tertiary alcohols leading to higher yield and easy elimination in water. In this study, yield were around $50 \mathrm{wt} . \%$. Higher yield are reachable with purification of chemical reagents and optimizing the catalyst. Moreover, acrylation with biobased acrylic acid could allow to reach $100 \%$ biorenewable carbon content.

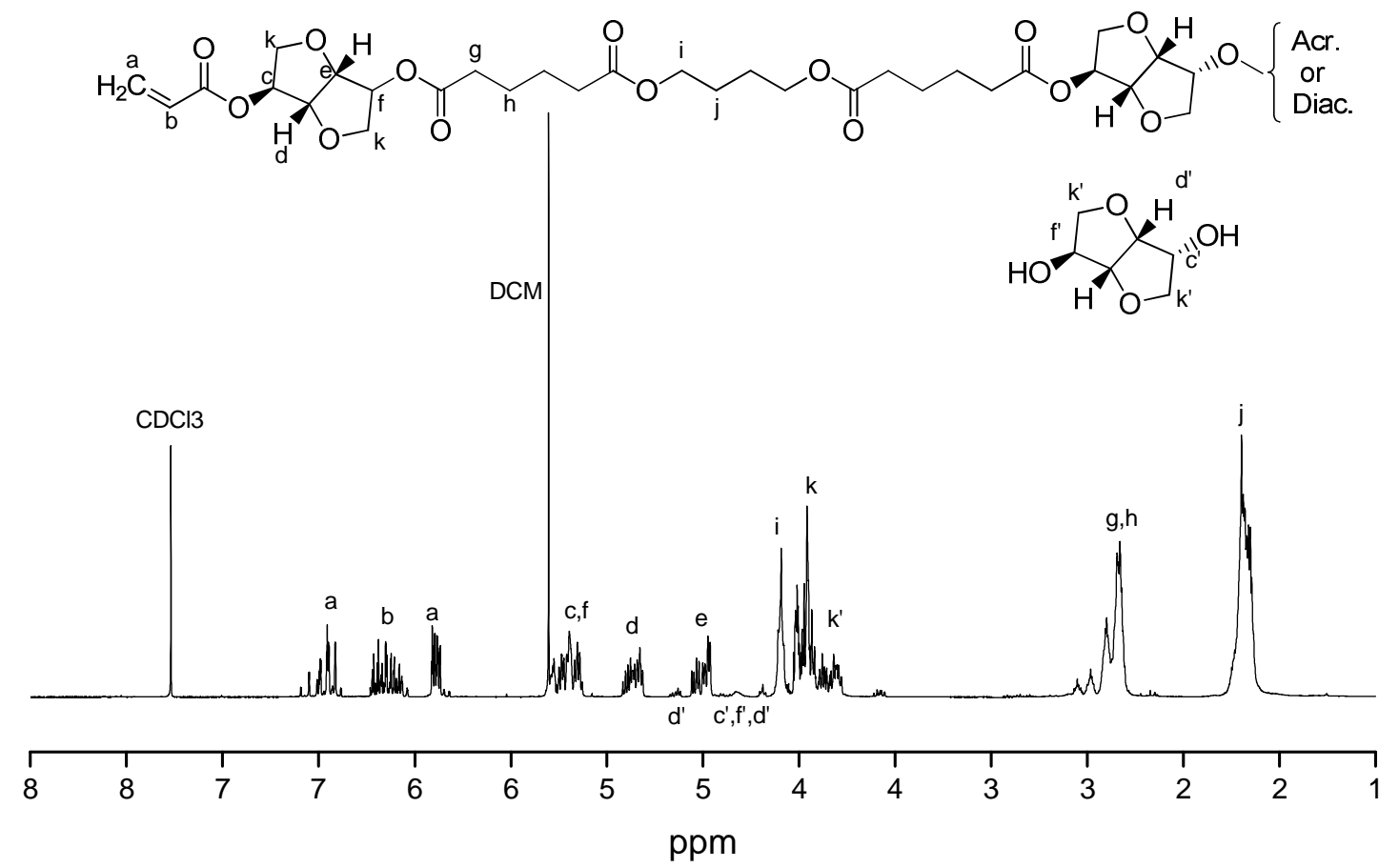

Figure $4:{ }^{1} \mathrm{H}$ NMR spectrum of oligo[BD:IS:C6]

As expected, molecular weights from SEC were overestimated compare to the $\mathrm{Mn}$ from the acid value, due to the SEC calibration made using polystyrene. As the structure of isosorbide induces slight hydrodynamic volume changes with the polystyrene calibration [13], Mn from acid value was preferred. An increase in diacid length increases the molecular weight. 
Table 1 : Chemical properties of the oligomers

\begin{tabular}{cccccccccc}
\hline Units & & & $\mathrm{Mn}$ & $\mathrm{Mw} / \mathrm{Mn}$ & $\mathrm{AV}$ & $\mathrm{DPn}$ & $2 \mathrm{f}$ & $\mathrm{AV} \mathrm{Mn}$ & $\mathrm{BRC}$ \\
& $\begin{array}{c}\text { Feed } \\
\text { composition }\end{array}$ & $\begin{array}{c}\mathrm{NMR} \\
\text { composition }\end{array}$ & $\begin{array}{c}\mathrm{SEC} \\
\mathrm{g} / \mathrm{mol}\end{array}$ & $\mathrm{SEC}$ & $\begin{array}{c}\mathrm{mg} \text { of } \\
\mathrm{KOH} / \mathrm{g}\end{array}$ & & & $\mathrm{g} / \mathrm{mol}$ & $\%$ \\
\hline oligo[BD:C4] & {$[1.1: 1]$} & - & 500 & - & - & - & - & 300 & 71 \\
oligo[IS:C4] & {$[1.1: 1]$} & - & 700 & 1.8 & 76 & 4.8 & - & 700 & 81 \\
oligo[BD:IS:C4] & {$[0.33: 0.97: 1]$} & {$[0.33: 0.97: 1]$} & 900 & 1.6 & 65 & 3.9 & 40 & 600 & 84 \\
oligo[BD:IS:C6] & {$[0.33: 0.97: 1]$} & {$[0.44: 0.86: 1]$} & 1000 & 2.1 & 65 & 3.6 & 52 & 600 & 85 \\
oligo[BD:IS:C9] & {$[0.33: 0.97: 1]$} & {$[0.44: 0.86: 1]$} & 1400 & 1.7 & 74 & 3.1 & 39 & 600 & 90 \\
oligo[PEG200:IS:C4] & {$[0.33: 0.97: 1]$} & {$[0.47: 0.83: 1]$} & 1200 & 1.7 & 67 & 3.6 & 47 & 600 & 72
\end{tabular}

The influence of the diacid length and diol nature can be seen in Table 2. The rigid V-shape of isosorbide leads to high viscosity. Starting with the reference [IS:C4] it can be noted that there is an increase of viscosity for oligo[IS:BD:C4] and then a decrease when the diacid length increases. The impact of the flexibility of the diol is confirmed with a significant drop in viscosity when using PEG. Glass transition temperatures match the literature values with oligo[BS:C4] around $-30^{\circ} \mathrm{C}$ [27]. An increase of diacid length decreases the $\mathrm{Tg}$ but interestingly, BD and PEG part leads to similar Tg values. It should be noticed that very high content of Bio Renewable Carbon content is very high, with values ranging from 71 to 90 .

Table 2 : Viscosity and Tg of the synthesized polyesters acrylate oligomers.

\begin{tabular}{lcc} 
& Viscosity (resin) & $\mathrm{Tg}^{\text {a) }}$ \\
Polyester Acrylate & Pa.s & ${ }^{\circ} \mathrm{C}$ \\
\hline oligo[BD:C4] & crystallized & -39 \\
oligo[IS:C4] & 50 & 35 \\
oligo[BD:IS:C4] & 93 & -7 \\
oligo[BD:IS:C6] & 3.8 & -17 \\
oligo[BD:IS:C9] & 2.6 & -25 \\
oligo[PEG200:IS:C4] & 5.6 & -5
\end{tabular}

a) Glass transition temperature obtained by DSC with 3wt.\% of BPO after 2 heat cycles 
Influence of the structure of the oligomer on photopolymerization reaction

Knowing the willingness of isosorbide to turn yellow under oxidation, inone of the oligomers synthesized absorb over $390 \mathrm{~nm}$ which allows the use of the LED at $395 \mathrm{~nm}$ and ITX as photoinitiator. Therefore, photopolymerization experiments using isopropylthioxanthone as photoinitiator and ethyl-4-dimethylaminobenzoate as coinitiator (1:3 wt. \%) were performed under $395 \mathrm{~nm}$ irradiation at $100 \mathrm{~mW} / \mathrm{cm}^{2}$. As can be seen in Figure 5 , the oligomer with the highest content in isosorbide oligo[IS:C4], leads to an early vitrification in the system that reduces the maximal degree of conversion obtained after 50s of irradiation. This could be attributed to the compact form of isosorbide compared to oligo[BD:IS:C4] where the introduction of butanediol as spacer renders the acrylate functions more accessible (Figure 5). As the chain length of the diacid increases ( $\mathrm{C} 4$ to $\mathrm{C} 9$ ), the mobility increases and allows to reach conversion higher than $90 \%$ for oligo[BD:IS:C9]. The rate of conversion Rp follows the same tendency. When comparing the effect of a PEG200 in oligo[PEG200:IS:C4] compared to oligo[BD:IS:C4], a higher conversion was found as a result of the more important flexibility [32].
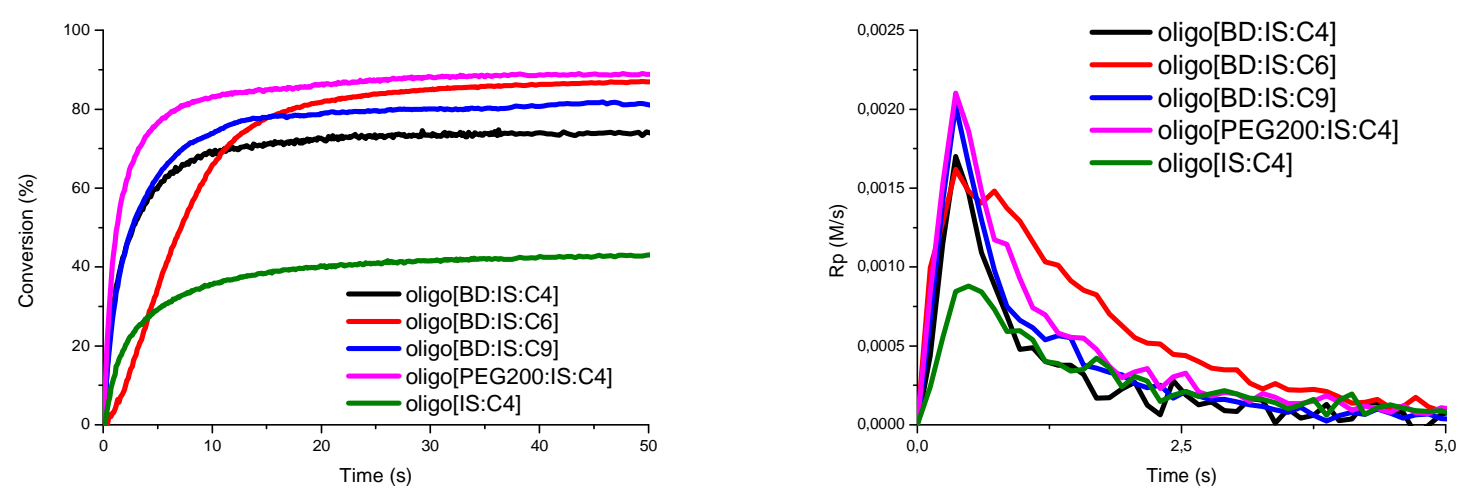

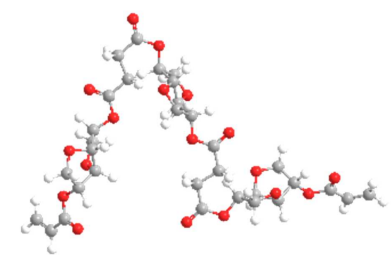

Oligo[IS:C4]

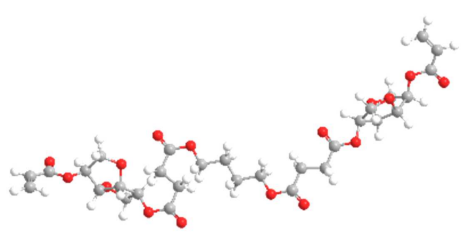

Oligo[IS :BD :C4

Figure 5 : Effect of the diacid length on a) conversion and b) rate of polymerization as a function of irradiation time under LED at $100 \mathrm{~mW} / \mathrm{cm}^{2}$ for oligomer with diacid length variation and reference. C) comparison of the structures of oligo[IS:C4] and Oligo[IS:BD:C4]. 
Table 3: Thermomechanical properties for the polyesters acrylates

\begin{tabular}{|c|c|c|c|c|c|c|c|c|}
\hline Polyester acrylate & $\begin{array}{l}\text { AV Mn } \\
\mathrm{g} / \mathrm{mol}\end{array}$ & $\begin{array}{c}D C^{a)} \\
\%\end{array}$ & $\begin{array}{l}\mathrm{Rp}^{\mathrm{a})} \\
\mathrm{Ms}^{-1}\end{array}$ & $\begin{array}{c}\mathrm{Tg} \\
{ }^{\circ} \mathrm{C} \pm 5\end{array}$ & $\begin{array}{c}\mathrm{DC} \text { b) } \\
\%\end{array}$ & $\begin{array}{c}\mathrm{T} \alpha \\
{ }^{\circ} \mathrm{C} \pm 5\end{array}$ & $\begin{array}{c}\mathrm{Mc} \\
10^{3} \mathrm{~g} / \mathrm{mol}\end{array}$ & $\begin{array}{l}\text { FWHM } \\
{ }^{\circ} \mathrm{C} \pm 10\end{array}$ \\
\hline oligo[IS:C4] & 700 & 45 & $8.79 .10^{-4}$ & 35 & 83 & 34 & 259 & 25 \\
\hline oligo[BD:IS:C4] & 600 & 74 & $1.70 .10^{-3}$ & -7 & 86 & 19 & 14 & 15 \\
\hline oligo[BD:IS:C6] & 600 & 91 & $1.62 .10^{-3}$ & -17 & 93 & 14 & 4 & 30 \\
\hline oligo[BD:IS:C9] & 600 & 97 & $2.02 .10^{-3}$ & -25 & 100 & -6 & 3 & 25 \\
\hline oligo[PEG200:IS:C4] & 600 & 89 & $2.10 .10^{-3}$ & -6 & 97 & -4 & 32 & 15 \\
\hline
\end{tabular}

a) Obtained under $100 \mathrm{~mW} / \mathrm{cm}^{2}$ LED irradiation at $395 \mathrm{~nm}$ coupled with FTIR. b) Obtained using $1 \mathrm{~J} / \mathrm{cm}^{2}$ irradiation using a LED irradiation at $395 \mathrm{~nm}$ on a belt conveyor.

Photopolymerization of films under belt conveyor at high light intensity was performed for all formulations. Interestingly, the high intensity and the heat evolved by the belt conveyor afford a higher final conversion and tack-free surface for all samples (Table 3). The dynamical mechanical analysis and DSC were performed on the basis of three cycles. The values reported in Table 3 correspond to those obtained on the second cycle. The oligomers exhibit $\mathrm{Tg}$ or $\mathrm{T} \alpha$ ranging from -25 to $+35^{\circ} \mathrm{C}$ and -6 to $+34^{\circ} \mathrm{C}$, respectively. As expected, it can be seen that the high isosorbide content leads to high $\mathrm{Tg}$ and $\mathrm{T} \alpha$ values. The values of FWHM are quite close for all system, a fact which is in line with the very similar values of $\mathrm{Mw} / \mathrm{Mn}$ (Table 1). The high FWHM value of $30^{\circ} \mathrm{C}$ for oligo[BD:IS:C6] corresponds to the high $\mathrm{Mw} / \mathrm{Mn}$ value of 2.1 .

Figure 6 shows that all films have the same value at the glassy plateau. Interestingly, there is a clear difference of behavior in the storage modulus at the rubbery plateau which is related to the crosslinking density. The lowest crosslinking density was found for oligo[IS:C4], a fact which could be attributed to the relatively low conversion (Table 3 ). Consequently, this compound exhibits almost a thermoplastic behavior, as can be seen from the shape of DMA curve. When introducing PEG or BD (oligo[IS:BD:C4] and oligo[IS:PEG200:C4]) the crosslinking density increases slightly. In addition, the DMA curves indicate that the structure of the oligomers allows a slight degree of crystallization. Concerning the rubbery plateau, the value of the storage modulus is typical of a low crosslinking density (Table 3) as can be expected from the relatively low ratio $2 f \%$ for these compounds. Increasing the diacid chain length ( $\mathrm{C} 6$ or $\mathrm{C} 9$ ) leads to higher values of the storage modulus by virtue of the more flexible chains which allows full conversion. A typical thermoset behavior is observed. Obviously, the highest flexibility of C9 compared to $\mathrm{C} 6$ leads to lower storage modulus. 


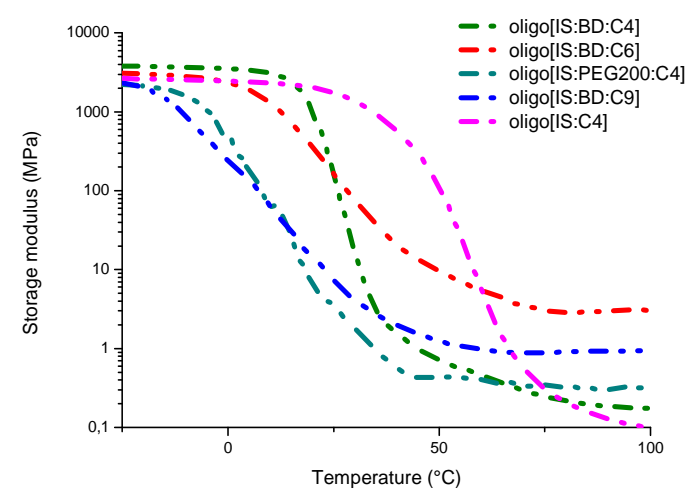

Figure 6: Change in storage modulus with the temperature for the photopolymerized films.

Biobased polyester acrylates in coating application

In order to develop formulations suitable for coating application, the viscosity of the biobased polyester acrylates is too high. Reactive diluent have to be added keeping in mind that the whole BRC of the formulation would possibly decrease. Therefore, the solubility (measured by saturation method) of several oligomers was tested in few reactive diluents as shown in Table 4.

Table 4 : Solubility of the PEA in various acrylate monomers as reactive diluents

\begin{tabular}{cc|cccc}
\hline & & THFA & HDDA & IBOA & 3 DA \\
Polyester Acrylate & Polarity & 0 & 1 & 2 & 3 \\
\hline oligo[IS:C4] & 0 & + & + & + & - \\
oligo[PEG200:IS:C4] & 1 & + & + & + & + \\
oligo[BD:IS:C4] & 2 & + & + & + & + \\
oligo[BD:IS:C6] & 3 & + & - & + & + \\
oligo[BD:IS:C9] & 4 & + & - & + & + \\
oligo[BDxISyC12] & 5 & + & - & + & +
\end{tabular}

As expected, an increase in diacid length decreases the polarity and solubility in more apolar reactive diluent such as decanediol diacrylate 3DA. Therefore, 3DA which could be biobased $(\mathrm{BRC}=60 \%)$, was chosen as best reactive diluent for this set of oligomers. The composition of the oligomer/monomer formulations is shown in Table 5. It can be seen that the maximum conversion obtained after $50 \mathrm{~s}$ are much higher than for the neat oligomers, a fact which is merely attributed to the lower viscosity reached by the formulation. However, 
the oxygen inhibition is expected to be higher and counterbalance the beneficial effect of the higher mobility. Overall, the rates of photopolymerization are lower than for the neat oligomers.

Table 5: Properties of oligomer/monomer formulations

\begin{tabular}{ccc|ccccc} 
& $\begin{array}{c}\mathrm{Rp}^{\mathrm{max}} \\
\mathrm{mol}^{-1} \cdot \mathrm{g}^{-1}\end{array}$ & $\begin{array}{c}\mathrm{DC} \\
\%\end{array}$ & $\begin{array}{c}\text { Conversion } \\
\%\end{array}$ & $\begin{array}{c}\mathrm{T \alpha} \\
{ }^{\circ} \mathrm{C} \pm 5\end{array}$ & $\begin{array}{c}\mathrm{FWHM} \\
{ }^{\circ} \mathrm{C} \pm 10\end{array}$ & $\begin{array}{c}\mathrm{Mc} \\
10^{3} \mathrm{~g} / \mathrm{mol}\end{array}$ & $\begin{array}{c}\mathrm{BRC} \\
\%\end{array}$ \\
\cline { 2 - 8 } & \multicolumn{7}{c}{ PEA:3DA 40:60 wt.\% } \\
oligo[PEG200:IS:C4] & $2.89 .10^{-3}$ & 74 & 98 & 15 & 35 & 0.9 & 68 \\
oligo[BD:IS:C6] & $3.45 .10^{-3}$ & 80 & 98 & 10 & 40 & 0.3 & 73 \\
oligo[BD:IS:C9] & $2.84 .10^{-3}$ & 93 & 100 & 10 & 50 & 0.6 & 75 \\
& \multicolumn{7}{c}{ PEA:3DA:ISGMA 30:50:20 wt.\% } \\
\cline { 2 - 8 } oligo[BD:IS:C6] & $1.35 .10^{-3}$ & 90 & 95 & 35 & 60 & 0.7
\end{tabular}

Three of the previous formulations were chosen to make coatings under LED-belt conveyor system. Comparing the results in Table 5 to that obtained for the neat oligomers in Table 3 shows that both $\mathrm{Tg}$ and FWHM increase in the presence of reactive diluent, a fact which is due to the relatively short chain introduced by 3DA in the oligomer network. Interestingly, the $\mathrm{BRC}$ is around $68-75 \%$, which is quite high for a low viscosity formulation.

Influence of an isosorbide acrylate reactive diluent.

It is interesting to definitively ensure the beneficial effet of the isosorbide moiety in the thermomechanical properties of a resin. For this purpose, isosorbide glycidyl acrylate (ISGMA) was introduced at 20wt.\% in the oligo[BD:IS:C6] : 3DA formulation. First, a significant increase of viscosity was noticed, from 0.3 to $0.6 \mathrm{~Pa}$.s with addition of ISGMA. Secondly, as can be seen on Figure 7, the reactivity slows down and Rp noticeably decreases by $39 \%$. Nevertheless, the mobility of the spacer allows the system to reach the same maximal conversion of about $90 \%$. Again, the effect of the V-shape of isosorbide can be seen in Figure 7 with a shift of maximum of $\tan \delta$ curve. In addition, the increase of FWHM could be explained by a higher heterogeneity in the network of the ternary composition where each crosslinking node has a different flexibility. This shows that tunable properties could be effectively obtained. 

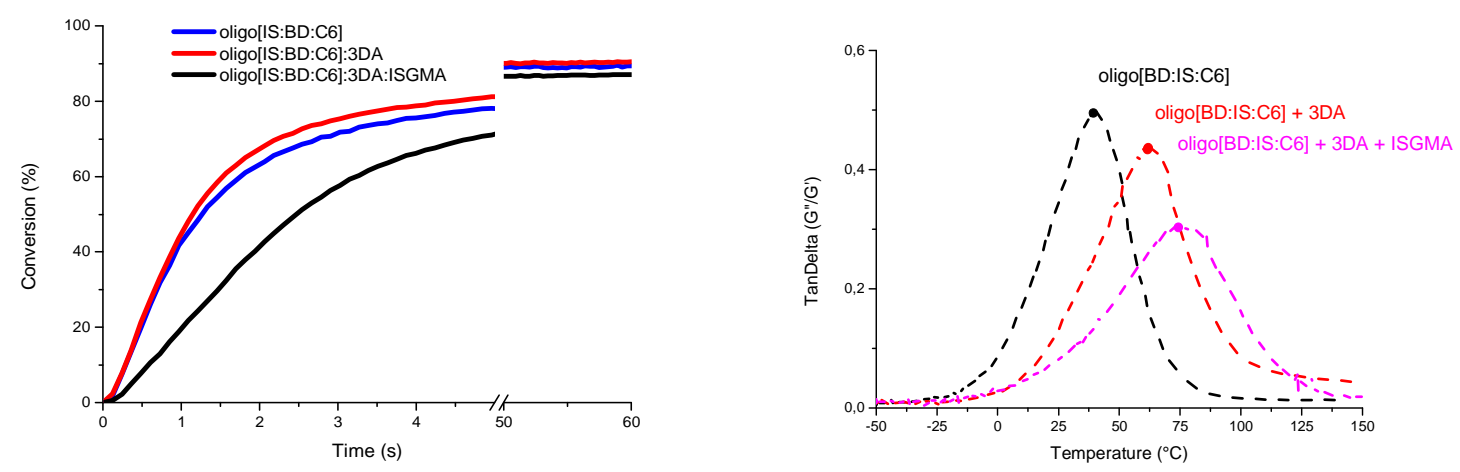

Figure 7: Left: conversion curve for oligo[IS:BD:C6]:3DA:ISGMA under irradiation, Right:

Change of $\tan \delta$ for oligo[IS:BD:C6], with 3DA and with ISGMA.

It was previously reported that there is a link between crosslinking density, flexible segment and abrasion resistance for polyurethane acrylate [33]. From that perspective, the diols PEG200 and BD used in this paper part could dissipate stress through elastic deformation while the rigid V-shape of isosorbide could maintain stiffness. Use of 2,3-butanediol may afford a spacer while restraining from too high mobility. However, 2,3-butanediol is not biobased at all. Recently other diol as syringaresinol [32], resveratrol or curcumin were compared to isosorbide, showing great interest for thermal resistance. Another approach would be to vary the structure of the diacid. For example, bio-based terephtalic acid has been used as rigid diacid in thermoset. From the point of view of acrylation process, greener solvents and use of (hydroxyethyl)methacrylate, epichlorhydrine or acrylic acid instead of acryloyl chloride would be valuable alternatives [33].

\section{Conclusions}

Several oligomers with a high bio-renewable carbon (BRC) content were successfully synthesized and characterized. Polyester acrylate (PEA) resin based on poly(butylene succinate) (PBS) and isosorbide were synthesized varying the diacid chain length (from C4 to $\mathrm{C} 12$ ) and the diols (butanediol and polyethyleneglycol). The effect of the composition on the stiffness of photopolymerized coatings was studied. Structure-property relationships were investigated. The synthesized oligomers with the shortest flexible segments were used to form thin coatings exhibiting high cure speed and high BRC. 


\section{References}

[1] R. Schwalm, UV coatings basics, recent developments and new applications, Elsevier, Amsterdam; London, 2007.

[2] B. Cok, I. Tsiropoulos, A.L. Roes, M.K. Patel, Succinic acid production derived from carbohydrates: An energy and greenhouse gas assessment of a platform chemical toward a biobased economy, Biofuels Bioprod. Biorefining. 8 (2014) 16-29. doi:10.1002/bbb.1427.

[3] P. Poltronieri, O.F. D'Urso, eds., Biotransformation of agricultural waste and by-products: the food, feed, fibre, fuel (4F) economy, Elsevier, Amsterdam ; Boston, 2016.

[4] International Renewable Energy Agency, Production of bio-ethylene (2013).

[5] D. Tian, K.T. Quisenberry, M.K. Boggiano, L.W. Leininger, S.L. Scheuering, J.S. Ross, Floor Coating Formulations Obtained from 100\% Natural, Renewable or Biobased Materials, (2017).

[6] A. Mhanna, Synthesis and formulation of photopolymerisable monomers derived from biomass: application for Braille printing, Université de Bourgogne (2014)

[7] A.K. Vasishtha, R.K. Trivedi, G. Das, Sebacic acid and 2-octanol from castor oil, J. Am. Oil Chem. Soc. 67 (1990) 333-337.

[8] C. Dussenne, T. Delaunay, V. Wiatz, H. Wyart, I. Suisse, M. Sauthier, Synthesis of isosorbide: an overview of challenging reactions, Green Chem. 19 (2017) 5332-5344.

[9] R.M. de Almeida, J. Li, C. Nederlof, P. O'Connor, M. Makkee, J.A. Moulijn, Cellulose Conversion to Isosorbide in Molten Salt hydrate Media, ChemSusChem. 3 (2010) 325-328.

[10] K.W. Buck, J.M. Duxbury, A.B. Foster, A.R. Perry, J.M. Webber, Observations on esterification reactions, Carbohydr. Res. 2 (1966) 122-131.

[11] S.-S. Baek, S.-H. Jang, S.-H. Hwang, Sustainable isosorbide-based transparent pressure-sensitive adhesives for optically clear adhesive and their adhesion performance: Isosorbide-based transparent pressure-sensitive adhesives, Polym. Int. 66 (2017) 1834-1840.

[12] Roquette Freres, High-viscosity polyester with improved impact properties, US20180155493A1.

[13] B.A.J. Noordover, V.G. van Staalduinen, R. Duchateau, C.E. Koning, van Benthem, M. Mak, A. Heise, A.E. Frissen, J. van Haveren, Co- and Terpolyesters Based on Isosorbide and Succinic Acid for Coating Applications: Synthesis and Characterization, Biomacromolecules. 7 (2006) 34063416.

[14] J.M. Sadler, F.R. Toulan, G.R. Palmese, J.J. La Scala, Unsaturated polyester resins for thermoset applications using renewable isosorbide as a component for property improvement, J. Appl. Polym. Sci. 132 (2015) 42726.

[15] L. Jasinska, C.E. Koning, Unsaturated, biobased polyesters and their cross-linking via radical copolymerization, J. Polym. Sci. Part Polym. Chem. 48 (2010) 2885-2895. 
[16] A.C. Fonseca, I.M. Lopes, J.F.J. Coelho, A.C. Serra, Synthesis of unsaturated polyesters based on renewable monomers: Structure/properties relationship and crosslinking with 2-hydroxyethyl methacrylate, React. Funct. Polym. 97 (2015) 1-11.

[17] Y. Xu, G. Hua, M. Hakkarainen, K. Odelius, Isosorbide as Core Component for Tailoring Biobased Unsaturated Polyester Thermosets for a Wide Structure-Property Window, Biomacromolecules. 19 (2018) 3077-3085.

[18] J.M. Sadler, A.-P.T. Nguyen, F.R. Toulan, J.P. Szabo, G.R. Palmese, C. Scheck, S. Lutgen, J.J. La Scala, Isosorbide-methacrylate as a bio-based low viscosity resin for high performance thermosetting applications, J. Mater. Chem. A. 1 (2013) 12579.

[19] N.G. Moon, F. Mazzini, A.M. Pekkanen, E.M. Wilts, T.E. Long, Sugar-Derived Poly( $\beta$-thioester)s as a Biomedical Scaffold, Macromol. Chem. Phys. 219 (2018) 1800177.

[20] L. Fertier, M. Ibert, C. Buffe, R. Saint-Loup, C. Joly-Duhamel, J.-J. Robin, O. Giani, New biosourced UV curable coatings based on isosorbide, Prog. Org. Coat. 99 (2016) 393-399.

[21] M. Ibert, C. Buffe, R. Saint-Loup, L. Fertier, O. Giani, J.-J. Robin, C. Joly-Duhamel, Cross-linkable compositions based on compounds of methacrylated derivatives of dianhydrohexitol, FR3003574B1, 2014.

[22] J. Łukaszczyk, B. Janicki, J. Kożuch, H. Wojdyła, Synthesis and Characterization of Low Viscosity Dimethacrylic Resin Based on Isosorbide, J. Appl. Polym. Sci. 130 (2013) 2514-2522.

[23] S. Kim, J.K. Cho, S. Shin, B.-J. Kim, Photo-curing behaviors of bio-based isosorbide dimethacrylate by irradiation of light-emitting diodes and the physical properties of its photocured materials, J. Appl. Polym. Sci. 132 (2015) 42726.

[24] T. Nguyen, B. Kim, Y.-J. Kim, S.-H. Lee, S. Shin, J.K. Cho, Synthesis of the bio-based alternative to Bis-GMA and its application to photo-polymerizable adhesives, Int. J. Adhes. Adhes. 80 (2018) $60-65$.

[25] H.R. Kricheldorf, G. Behnken, M. Sell, Influence of Isosorbide on Glass-Transition Temperature and Crystallinity of Poly(butylene terephthalate), J. Macromol. Sci. Part A. 44 (2007) 679-684.

[26] R.-T. Duan, Q.-X. He, X. Dong, D.-F. Li, X.-L. Wang, Y.-Z. Wang, Renewable Sugar-Based Diols with Different Rigid Structure: Comparable Investigation on Improving Poly(butylene succinate) Performance, ACS Sustain. Chem. Eng. 4 (2016) 350-362.

[27] X. Huang, C. Li, W. Zhu, D. Zhang, G. Guan, Y. Xiao, Ultraviolet-induced crosslinking of poly(butylene succinate) and its thermal property, dynamic mechanical property, and biodegradability, Polym. Adv. Technol. 22 (2011) 648-656.

[28] J. Łukaszczyk, B. Janicki, A. Frick, Investigation on synthesis and properties of isosorbide based bis-GMA analogue, J. Mater. Sci. Mater. Med. 23 (2012) 1149-1155. 
[29] R. Nyquist, Alkenes and Other Compounds Containing C=C Double Bonds, in: Interpret. Infrared Raman Nucl. Magn. Reson. Spectra, Elsevier, 2001: pp. 55-91.

[30] K. Menard, Dynamic Mechanical Analysis: A Practical Introduction, CRC Press, (1999).

[31] European Committee for Standardization, Bio-based products - Overview of methods to determine the bio-based content, CEN/TR 16721:2014 (2014)

[32] W.D. Cook, J.S. Forsythe, N. Irawati, T.F. Scott, W.Z. Xia, Cure kinetics and thermomechanical properties of thermally stable photopolymerized dimethacrylates, J. Appl. Polym. Sci. 90 (2003) 3753-3766.

[33] L. Marasinghe, C. Croutxé-Barghorn, X. Allonas, A. Criqui, Effect of reactive monomers on polymer structure and abrasion resistance of UV cured thin films, Prog. Org. Coat. 118 (2018) 22-29.

[34] J. Pang,M. Zheng,R. Sun,A. Wang,X. Wang,T. Zhang,. (2016). Synthesis of ethylene glycol and terephthalic acid from biomass for producing PET. Green Chem. 18 (2016) 342-359 